\title{
Enhanced UV-Visible Absorbance Detection in Capillary Electrophoresis Using Modified T-Shaped Post-Column Flow Cell
}

\author{
Kwanseop Lim, Suhyeeon Kim, and Jong Hoon Hahn \\ National Research Laboratory for Advanced Biotechnology and Biomedical Aicroinstrumentation, \\ Diwision of Molectlar and Life Sciences, Pohang Lniversity of Science and Technologv, Pohang 790-784, Korea \\ Received October 22, 2001
}

\begin{abstract}
The construction of the T-shaped post-column flow cell has been changed to enhance the practicability as a UV-visible absorbance detector for capillary electrophoresis. In this new design a rectangular cube-shaped inner structure is employed. which completely fits the outer rectangular tubing. This arrangement has greatly facilitated the fabrication of the T-cells. In addition. the volume for the auviliary flow has been dramatically reduced down to $300 \mu \mathrm{L}$. and its volume flow rate is optimized at $4.2 \mu \mathrm{L} / \mathrm{min}$. The short optical path length in the sheath flows ( $500 \mu \mathrm{m}$ on each side) minimizes background absorption and thus enlances its performance in low-UV wavelengths. We have optimized the auxiliary flow rate at $50 \mu \mathrm{m} / \mathrm{s}$. so that migration times are insensitive to the flow rate. This optimization has improved repeatabilities in migration times and peak heights. A double-beam detection scheme using a pair of photodiodes is employed to increase the signal-to-noise ratio.
\end{abstract}

Keywords : Capillary electrophoresis. Post-column. Absorbance detection, Extended path length.

\section{Introduction}

Although capillary electrophoresis (CE) as a separation method has the advantages of rapid separation and high resolution. one of limitations is its detection capabilities. Absorbance. fluorescence electrochemical and refractive index have been the major detection modalities of $\mathrm{CE} .^{1-1 \S}$ Among them. on-column absorbance detection has been most commonly used for CE. The short path length inherent in capillaries of I.D. less than $100 \mu \mathrm{m}$. however limits the detection sensitivity that is achieved with absorbance detection. ${ }^{\text {. }:-2}$ Several attempts have been made to improve the detection sensitivity by extending the optical path length. Tsuda et $a$. used rectangular capillaries with widths up to 1 mm. and reported a 15 -fold sensitivity enhancement. ${ }^{23} \mathrm{Xi}$ and Yeung developed an axial illumination technique. and achieved a 7 -fold increase in sensitivity using a 50- $\mu \mathrm{m}$ I.D. capillary and 3-mm injection plugs. ${ }^{-4}$ Chervet $e t$ al. extended the optical path length by bending a capillary into a $Z$ shape. and demonstrated a 6 -fold improvement in the signal-tonoise ratio $(\mathrm{S} / \mathrm{N})$ using a $Z$-shaped flow cell with a $3-\mathrm{mum}$ bend. ${ }^{25}$ Moring et $a$. reported a 10 -fold improvement in detection limit with the use of Z-shaped cell. ${ }^{26}$ Rectangular capillaries are fragile in nature and hard to be used in routine works. The axial illumination method demands special arrangements among the capillary column. the light source. and the detector. Although the Z-shaped flow cells seem to be promising in that they are easily fabricated and compatible with commercial CE instruments. the bends in a Z-shaped capillary flow cell induce serious light scattering. In order to

\footnotetext{
"To whon correspondence should be addressed. E-mail: halnh postech.ac.kr

${ }^{\dagger}$ Present address: LG Electronic Institute of Technology; Seoul 137140 , Korea
}

minimize it. focusing the incident light with a special optics and offsetting the optics from the capillary axis are required.

We developed a method of extending the optical path length for absorbance detection in CE. where an "upsidedown $\mathrm{T}^{\prime \prime}$ shaped flow cell formed by connecting the end of a capillary column with a 3-mm microchannel is employed. and by axially illuminating the microchannel with light. the full length of the channel can be used for the optical path. 27.28 An 8-fold S/N improvement over conventional on-columm detection was attained. Our T-shaped flow cell has several advantages over the $Z$-shaped one. For example, since the $T$ shaped flow cell doesn't have any bent parts along the optical path. the optical coupling is straightforward. Through some simple modifications. post-column derivatization and fluorescence detection can be accomplished. Finally. our flow cells can be applied to nearly all kinds of coherent or incoherent optical detection methods. absorption, fluorescence and thermo-optical absorption. to name a few. However, the T-shaped flow cell reported had drawbacks in design. The upside-down $\mathrm{T}$ channel was formed inside a cylindrical structure. whereas the whole flow cell itself was assembled using a square quartz tubing. Therefore. it was extremely difficult to attain good optical alignment. where the axis of the 3-1mm microchannel should be normal to two opposite faces of the square tubing. In the previous design. the volume and rate for the auxiliary flow were not optimized. and thus an excessive amount of the fluid was consumed and also the repeatabilities in migration time and peak height were poor.

In this work, we have improved the design of the T-shaped flow cell to greatly facilitate its fabrication and optical alignment and to minimize the volume for the auxiliary flow and to attain high performance for quantitative analy sis. The UV-visible absorbance detector setup has been changed to enhance practicability by emploỵing a double-beam arrange- 
ment with a pair of photodiodes.

\section{Experimental Section}

T-shaped post-column flow cell. The T-shaped postcolunin flow cell is sinilar to those used in our previous works. ${ }^{27.25}$ Therefore. only the modifications made for improving its fabrication and performance are described in detail. Figure I shows the construction of the T-shaped postcolunin flow cell. The inner part of the cell comprises a rectangular cube structure. inside which there is an upsidedown $T$-shaped channel formed by connecting the end of the capillary column with a $3-\mathrm{mm}$ nicrochannel orthogonally (Figure l(b)).

(a)

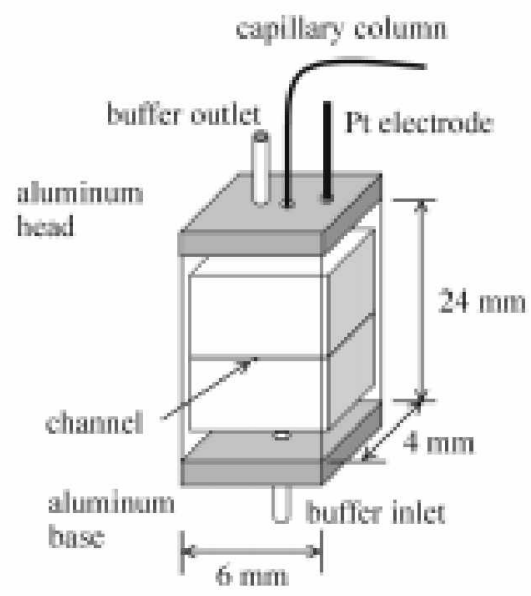

The fabrication process of the T-shaped post-column flow cell is shown in Figure 2. In the lower part. a 3-mm microchannel is fonmed in the middle of the $3 \mathrm{~mm} \times 6 \mathrm{~mm}$ surface of a borosilicate rectangular cube $(3 \mathrm{~mm} \times 6 \mathrm{~mm} \times 10 \mathrm{~mm}$ ) along the direction of the 3-1mm side. The body of the channel is made by bisecting a piece of a fused-silica capillary (100 $\mu \mathrm{m}$ I.D. and $375 \mu \mathrm{m}$ O.D.; Polymicro Technologies. Phoenix. AZ, USA). In the upper part, a groove of $0.4-\mathrm{nm}$ width and 2-mm depth is made in the middle of the $6 \mathrm{~mm} \times 10 \mathrm{~mm}$ surface of a borosilicate rectangular cube $(3$ $\mathrm{mm} \times 6 \mathrm{~mm} \times 10 \mathrm{~mm}$ ) along the direction of the $10-\mathrm{mm}$ side. One end of a $45-\mathrm{cm}$ capillary columm (75 um I.D. and $375 \mu \mathrm{m}$ O.D.; Polymicro Technologies. Phoenix. AZ, USA) is fixed with an eposy in the groove so that the outlet of the

(b)
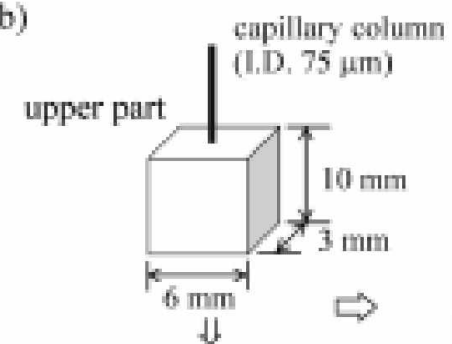

lower part

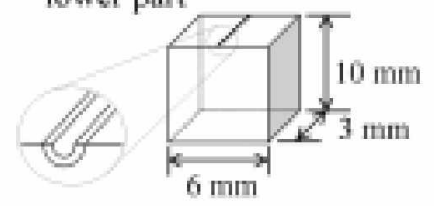

bisectod capillary

(ID. $100 \mu \mathrm{m})$

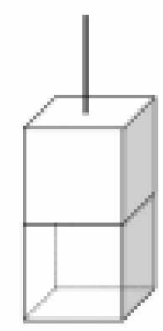

Figure 1. (a) Schematic of the T-shaped post-column flow cell. (b) Anatomy of the rectangular cube-shaped assembly in the flow cell.

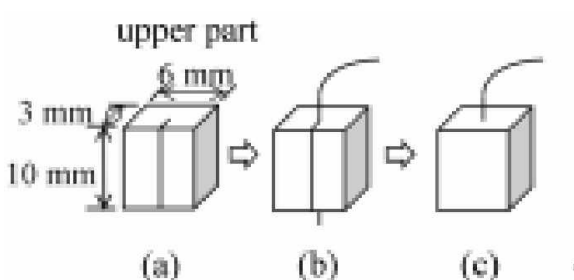

(a)

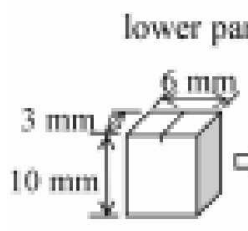

(d)

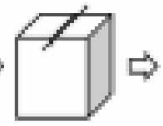

(c)
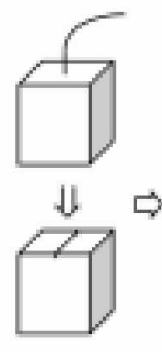

(g)

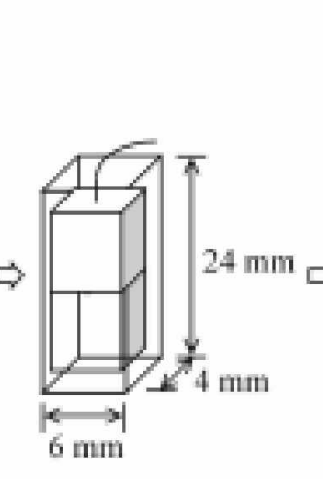

(h)

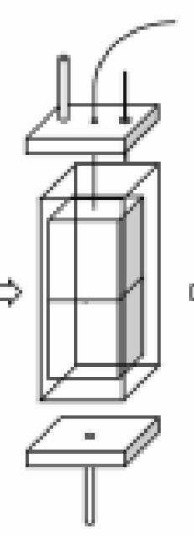

(i)

Figure 2. Fabrication process of the T-shaped post-colunn cell: (a) make a groove of 0.4-mm width and 2-mm depth in the middle of the 6 $\mathrm{mm} \times 10 \mathrm{~mm}$ surtace along the direction of the $10-\mathrm{mm}$ side; (b) fix a $45-\mathrm{cm}$ capillary column (75 $\mu \mathrm{m}$ I.D. and $375 \mu \mathrm{m}$ O.D.) in the groove using an epoxy, so that the outlet of the capillary is positioned at the center of the $3 \mathrm{~mm} \times 6 \mathrm{~mm}$ surface; (c) trim the excess capillary on the bottom surface; (d) make a groove of 0.4-mun width and 1-mun depth in the middle of the $6 \mathrm{~mm} \times 3 \mathrm{~mm}$ surface along the direction of the $3-$ min side: (e) fix a 4-17m capillary colunu (100 $\mu \mathrm{m}$ I.D. and $375 \mu \mathrm{m}$ O.D.) in the groove using an eposy; (f) trim the excess capillary and grind the fixed capillary by half ( $g$ ) put the upper and lower parts together using an epony resin so that the cross-sectional center of the capillary end sits on the middle of the longitudinal axis of the bisected capillary; (h) insert the rectangular cube-shaped assembly into the 24minn square tubing: (i) attach the aluninum head and base: (j) complete the fabrication. 


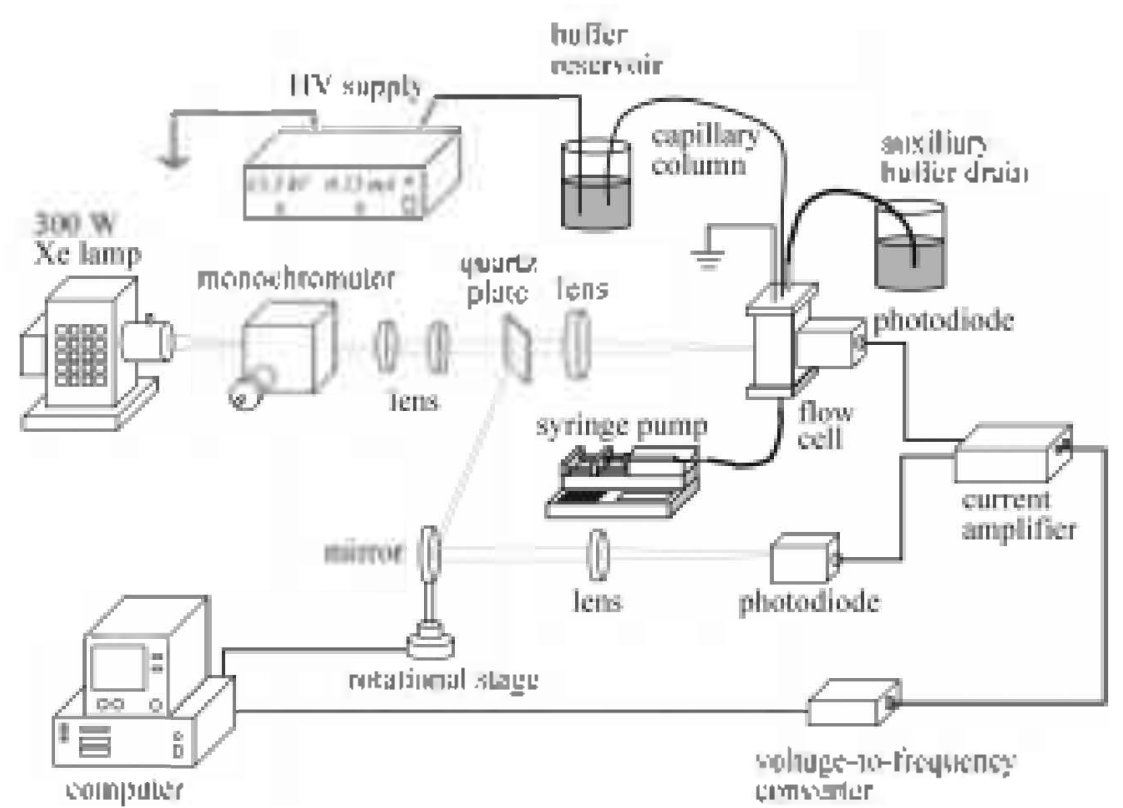

Figure 3. Schematic of $\mathrm{CE}$ apparatus with a double-beam UV-Vis absorbance detector employing the T-shaped post-column flow cell.

capillary is positioned at the center of the $3 \mathrm{~nm} \times 6 \mathrm{~mm}$ surface. The upside-down T-shaped channel is completed by putting the upper and lower parts together using an epoxy resin so that the cross-sectional center of the capillary end sits on the middle of the longitudinal axis of the bisected capillary. The outer part of the flow cell is assembled with a 24-num square quartz tubing (6 $\mathrm{nm} \times 4 \mathrm{~nm}$. $1 / 16^{*}$ thick: Wale Apparatus. Hellertown. PA, USA) and aluminum head and base.

CE system. Our experimental arrangement of a homemade CE system with the T-shaped post-column flow cell is shown in Figure 3. It employs a double-beam type detection system. A 300-W Xe lamp (6258: Oriel, Stratford. CT, USA) coupled with a monochromator (100M: American Holographics, Elmısford, NY. USA) is used as the monochromatic light source. Light is collinated by two plano-convex lenses (PLCX-25.4-10.3-UV. PLCX-25.4-51.5-UV: CVI Laser, Albuquerque, NM, USA) and then split into two beanus by a quartz plate $\left(1^{\prime \prime} \times 1\right.$ ". 1/16" thick: Wale Apparatus. Hellertown. PA. USA). The beam transmitted is used as probe beam, which is focused onto one end of the post-columm microchannel of the flow cell by a plano-convex lens (PLCX-50 0-77.3-UV; CVI Laser). and then detected by the first photodiode (S1336-8BQ: Hamamatsu. Japan) after passing through the microchannel. The beam reflected serves as a reference beam, and is directly detected by the second photodiode (S1336-8BQ; Hamamatsu. Japan).

Before running a CE separation. the intensity of reference beam is controlled with a mirror on the rotational stage so that the amplitude of the signal from the second photodiode is the same as that from the first one. The difference of the signals from the two photodiodes is amplified with a current amplifier ( 428 ; Keithley. Cleveland. OH, USA) and converted to a pulse-signal whose frequency is directly proportional to the amplified signal level. An IBM XT-compatible coniputer counts the number of pulses and stored it. A high voltage power supply (MHP 20-05D: IMACE. Seoul, Korea) is used to apply a $(+)$ high voltage across the fused-silica capillary of $45 \mathrm{~cm}$ length. The buffer solution for auxiliary flows is fed into the flow cell with a syringe pump (Syringe Infusion Punp 22; Harvard Apparatus, South Natick, MA, USA).

The CE setup for the on-column absorbance detection is essentially the same as that for the post-column detection except for some differences in detection part. A $70 \mathrm{~cm}$ fused-silica capillary is used as the CE column. A $100 \mu \mathrm{m} \times$ $200 \mu \mathrm{m}$ slit is used to defme the dimension of incident light on the detection window that is $45 \mathrm{~cm}$ from the injection end of the capillary colunn.

Reagents. All chemicals were of analytical-reagent grade and used without further purification. Rhodamine 6G. dansylamino acids. and all other inorganic chemicals were purchased from Sigma (St. Louis. MO. USA). Deionized water was prepared with a Mega-Pure system (Barnstead, Dubuque. IA. USA). Buffer was filtered through a $0.45 \mu \mathrm{m}$ syringe filter (cellulose nitrate; Whatman. Maidstone. UK) and degassed by sonication for $5 \mathrm{~min}$ just before use. Samples for $C E$ were prepared by dissolving pure compounds in the deionized water and serially diluted with the running buffer.

Capillary electrophoresis. The capillary column was pretreated with $0.1 \mathrm{M} \mathrm{NaOH}$, deionized water. and the rumning buffer in sequence. Each solution was pumped into the capillary for $5 \mathrm{~min}$ at a flow rate of $10 \mu \mathrm{L} / \mathrm{min}$ using a syringe pump. After each $C E$ running. the columm was rinsed with the running buffer for $1 \mathrm{~min}$. Sample injection was accomplished manually by siphoning with a height of $20 \mathrm{~cm}$ for 5 seconds. To carry out CE separation. a high voltage of $250 \mathrm{~V} / \mathrm{cm}$ was applied to the injection end of the capillary columm. As an excitation wavelength, $514 \mathrm{~nm}$ was chosen by the monochromator. In the post-column detection method. the auxiliary flow with a flow rate of $50 \mu \mathrm{m} / \mathrm{s}(4.2$ 
$\mu \mathrm{L} / \mathrm{min}$ ) was fed into the detection cell after the high voltage was applied.

\section{Results and Discussion}

In the previous design of the T-shaped post-column flow cell. the inner part has a cylindrical structure. ${ }^{27.28}$ Therefore. when the flow cell is assembled. extreme care must be taken so as to make the 3-num microchannel aligned normal to the faces of the square tubing. Although a stereomicroscope. a light illuminator, and micrometer-precision rotation/translation holders were used in assembling the cells, the success rate was less than $10 \%$. The present design provides. however. a rectangular cube-shaped inner structure that completely fits the outer rectangular tubing. and thus in contrast to the previous one, slight adjustment of only a single angle is required in assembling. This has greatly facilitated the fabrication of the T-cells and now the success rate in fabrication is over $90 \%$. It should be also noted that the volume for the auxiliary flow has been minimized in the new T-cells. The old type has the volume of $3800 \mathrm{~mm}^{3}$. whereas in the new type the volume is only $300 \mathrm{~mm}^{3}$. This. over 10 fold reduction in volume minimizes the consumption of the auxiliary fluid. In addition to these improvements. we have greatly reduced the potential background absorption by running buffers. High sensitivity in absorbance detection can often be realized by use of low-UV wavelengths. In this case, however, the use of minimally absorbing ruming buffers is strongly demanded. because high background absorbance increases baseline noise and decreases signal ${ }^{* 9}$ Compared with the old cell. the optical path length in the sheath flows has been reduced 7 times in the new cell, and now only $500 \mu \mathrm{m}$-thick sheath flows pass the ends of the microchannel. All these merits in the new design pronise practicability in sensitive absorbance detection to the $T$. shaped flow cells.

Figure 4 shows electropherogranıs of rhodamine $6 \mathrm{G}$, which were obtained using the on-colunn and post-column detection methods. The linits of detection (LODs) $(\mathrm{S} / \mathrm{N}=2)$ of rhodamine $6 \mathrm{G}$ in the on-column and post-colunn schemes are $1.4 \times 10^{-6} \mathrm{M}$ and $6.0 \times 10^{-8} \mathrm{M}$, respectively. Note that by using our $\mathrm{T}$-shaped post-colunn flow cell, a 24 -fold enhancement in $\mathrm{S} / \mathrm{N}$ has been achieved. This improvement in sensitivity is 3 times better than that obtained with the previous system. ${ }^{27}$ It seems that the change to the doublebeam schene is responsible for the higher gain in sensitivity of the present system. Further improvements in the sensitivity gain will be attained. if brighter light sources, or alternatively more sensitive detectors, such as photomultiplier tubes and avalanche photodiodes. are employed to reduce the background noise level.

In the last work. we observed that the migration time of a component, obtained in a systent with the T-cell was significantly longer than that in an on-colunun system. although the length from the injection end of the capillary column to the detection window was the same in both cases. The lengthened nigration times may be due to hydraulic pressure. (a)

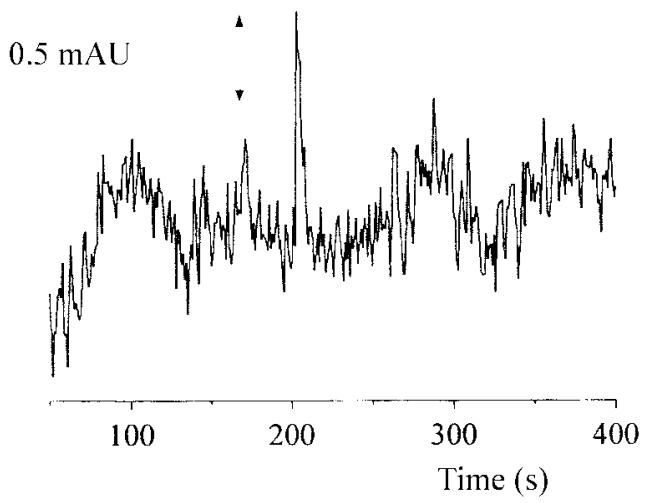

(b)

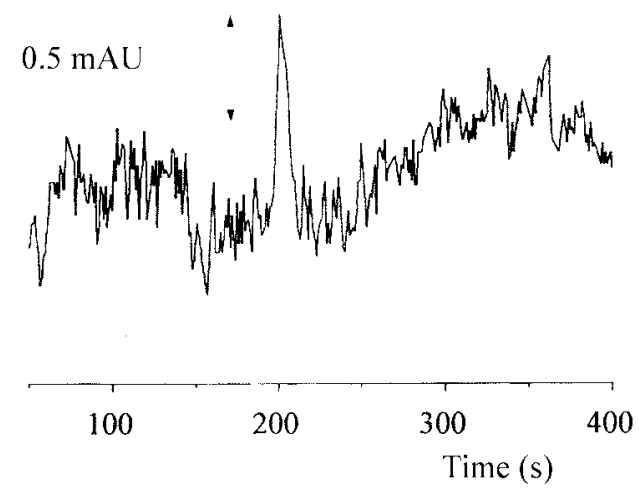

Figure 4. Electropherograms of (a) $2.0 \times 10^{-6} \mathrm{M}$ of rhodamine $6 \mathrm{G}$ by on-column detection and (b) $1.0 \times 10^{-7} \mathrm{M}$ of rhodamine $6 \mathrm{G}$ by post-column detection.

generated by the auxiliary flows. on the elute from the microchannel. We have investigated the dependence of the migration time on the flow rate of the auxiliary flows. As shown in Figure 5. the migration time is essentially constant up to $150 \mu \mathrm{m} / \mathrm{s}$, but over $200 \mu \mathrm{m} / \mathrm{s}$. the migration time significantly increases with the flow rate. In the present work, we have optimized the auxiliary flow at a flow rate of $50 \mathrm{~mm} / \mathrm{s}$, so that the difference in migration times between two systems is minimized. It is clearly shown in Figure 4. where we cannot see any discenible difference in the

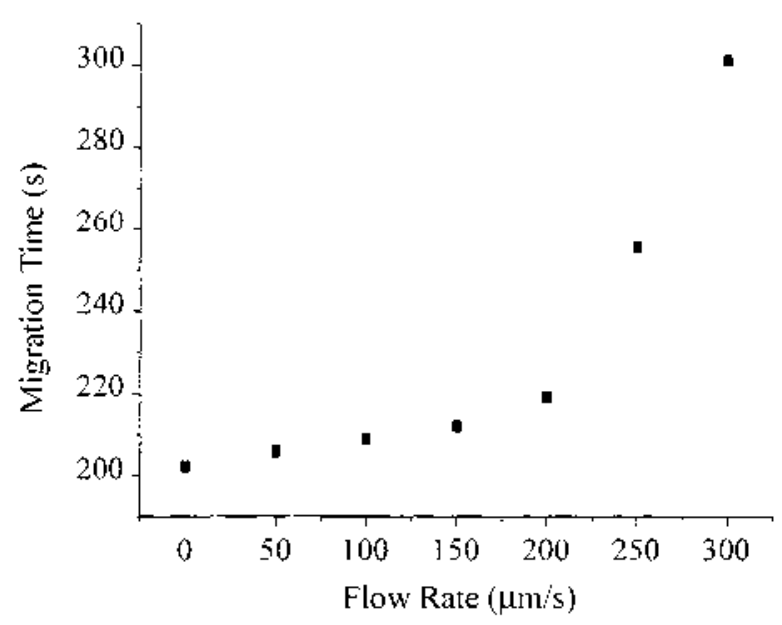

Figure 5. Migration times at various rates of the auxiliary flow. 


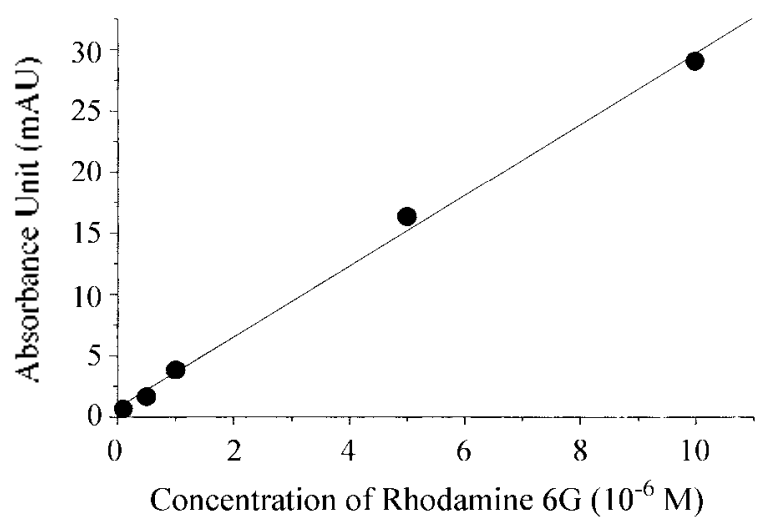

Figure 6. Linear relationship between concentrations and peak heights of thodamine $6 \mathrm{G}$ for $\mathrm{CE}$ analy sis using the T-shaped postcolunu flow cell.

migration times of rhodamine $6 \mathrm{G}$.

The hydraulic pressure imposed by the auxiliary flows may also transform the plug profile of electoosmotic flows into the parabolic profile of hydrodynamic flows, which causes the broadening of a band. Therefore. if there is serious instability in the rate of auxiliary flows, the width of a band fluctuates and so does its peak height. Since in contrast to the previous work. the flow rate is now in the region where the migration time and thus the peak height are insensitive to it. we have accomplished over two times better repeatabilities in the migration time and peak height of rhodamine $6 \mathrm{G}$ ( $1.8 \%$ and $2.4 \%$, respectively).

Because of the inproved LOD and repeatability, we have obtained a wider linear range of concentration (from $1.0 \times$ $10^{-7} \mathrm{M}$ to $1.0 \times 10^{-5} \mathrm{M}$ ) and a higher linear correlation coefficient ( $r=0.996)$ (Fig. 6). As in the previous study, we have observed that the calibration curve begins to flatten at about $1 \times 10^{-5} \mathrm{M}$, but any band broadening and tailing have not been observed up to about $1 \times 10^{-4} \mathrm{M}$. These observations strongly imply that the upper limit of the linearity of the post-column flow cells is mainly attributed to stray light. Since we have made the surfaces surrounding the ends of the microchannel black using an optically opaque epoxy to ensure only the axially propagating light to be detected, the loosely light-tight homemade system might be responsible for the stray light.

Figure 7 demonstrates the practicability of our CE setup equipped with the T-shaped post-column flow cell. An equimolar mixture of four dansyl-amino acids was successfully separated by the system. LODs of the dansyl-amino acids $(216 \mathrm{~nm})$ were almost the same as that of rhodamine 6G $(5 \mathrm{I}+\mathrm{nm})$. As mentioned above. absorbance detection at lowUV wavelengths necessitates the use of ninimally absorbing running buffers since high background absorbance significantly reduces $\mathrm{S} / \mathrm{N}$. Many buffers such as HEPES. CAPS. and Tris are inappropriate for use in low-UV detection. ${ }^{3031}$ We have used phosphate buffer for the detection of dansylamino acids at $216 \mathrm{~nm}$. which minimizes the effect of background absorption.

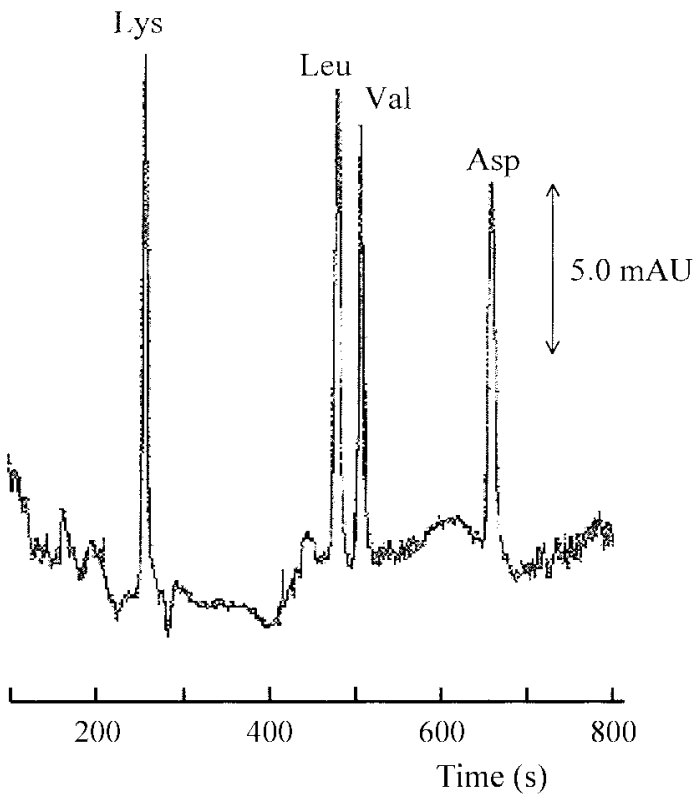

Figure 7. Electropherogram of dansyl-amino acids obtained using the T-shaped post-column flow cell. Capillary, $75 \mu \mathrm{m}$ I.D., $40 \mathrm{~cm}$ length; buffer, $10 \mathrm{mM}$ phosphate $(\mathrm{pH} 7.0)$; sample concentrations $4.0 \times 10^{-5} \mathrm{M}$ for each dansyl-amino acid; sample injection, 5 seconds at $20 \mathrm{~cm}$ height difference; detection wavelength, $216 \mathrm{~nm}$; applied voltage, $10 \mathrm{kV}(250 \mathrm{~V} / \mathrm{cm}$; Arg = dansyl-arginine; Leu = dansyl-leucine; $\mathrm{Val}=$ dansyl-valine; $\mathrm{Asp}=$ dansyl-aspartic acid.

\section{Conclusions}

The T-shaped flow cell for absorbance detection in CE has conceptually had many advantages over other detection cells with extended optical path lengths. When the concept was realized by the old design. several crucial drawbacks were found. such as the difficulty in aligning the optical axis of the cell, the poor repeatabilities in migration times and peak heights due to unoptimized flow rates for the sheath fluid. and the excessive cell volume for the sheath flow. In this work, by changing the design of the detection cell. while keeping the concept, we have solved most of the problems in the old design and thus endowed the T-shaped flow cell with higher practicability:

However. our T-shaped flow cell has several drawbacks to overcome. For example, the capillary column is permanently fixed to the flow cell and changing a column should be accompanied with fabrication of a new cell. fabrication of the flow cell is complicated and difficult, and using sheath flows needs additional complications. For practical use of the flow cell. a teclunique for inserting a capillary column into the flow cell through a guide tubing. a monolithic microfabrication process for the cell, and a simple mechanism for circulating the buffer in the flow cell should be developed.

The basic idea in the T-cell is connecting two microchannels orthogonally. In addition to the possible applications in developing highly efficient micro-detection cells. the idea can also be used to develop the injection devices for microfluidic systems. like sipping injectors, and to build 
three dimensional microfluidic systems.

Acknowledgment. J. H. Halun is very glad to express his thanks and respect to his teacher. Professor Kyung-Hoon Jung, through his contribution to this volume commenorating Prof. Jungs lifetime devotion to research and education. The authors are grateful to the Korea Science and Engineering Foundation for the financial support of this work (KOSEF 95-0501-05-03-3).

\section{References}

1. Swinney $\mathrm{K}$ : Bornhop, D. I. Electrophoresis 2000. 21. 1239.

2. Mainka. A.: Bächmann. K. J. Chromatogr. A 1997. 767. 241.

3. Li. C.: Martin. L. M. Anal. Biochent 1998. 263.72.

4. Wang. T.: Aiken. J. H.: Huie. C. W.: Hartwick. R. A. Anal Chent. $1991,63,1372$

5. Vorndran. A.: Oefner, P.: Scherz. H.: Bonn, G. Chomatographia $1992,33,163$.

6. Foret. F.: Fanali. S.: Nardi. A.: Boček P. Electrophoresis 1990. II. 780 .

7. Chen. M: Waldron. K. C.: Zhao. Y: Dovichi. N. J. Electrophonsis 1994. 15, 1290.

8. Gassmann E.: Kulo. J. E.: Zare R. N. Science 1985, 230.813.

9. Chen, D. Y: Adelheln. K. Cheng X. L.: Dotichi, N. I. Anatyst 1994. 119.349

10. Timperman. A. T.: Khatib. K.: Sweedler. J. V. Antll Chem. 1995. 67. 139

11. Kar. S.; Dasgupta, P. K.; Liu. H. Hwang, H. Anal. Chem. 1994.
66. 2537.

12. Kuhr. W. G.: Yeung. E. S. Anal Chent 1988. 60. 2642.

13. Chang. H.-T.: Yeung. E. S. Anal. Chem. 1995. 67. 1079

14. Craig. D. B.: Arriaga. E.: Wong. J. C. Y.: Lu. H.: Dovichi. N. I. Anal Chem $1998,70.39 \mathrm{~A}$.

15. Xue, Q: Yeung. E. S. Natwe 1995, 373.681.

16. Bornhop. D. J.: Dovichi. N. J. Anal. Chem 1986, 58.504.

17. Deng. Y.: Li. B. Appl. Opt 1998. 37.998.

18. Kitagishi. K.: Sato. Y. Electrophoresis 2001. 22. 3395.

19. Hu. T.: Zuo. H.: Riley. C. M.: Stobaugh. J. F.: Lunte. S. M. J. Chomatogr. A 1995. 716. 381.

20. Taylor. J. A.: Yeung, E. S. J. Chronatogr: 1991. $550,831$.

21. Grant. I. H. Steuer. W. J. Mficrocol. Sep. 1990. 2. 74.

22. Poppe H. Anal Chent Acta 1980. H1.59.

23. Tsuda. T.: Sweedler. J. V.: Zare. R. N. Anal Chen. 1990. 62. 2149.

24. Xi, X: Yeung. E. S. Appl. Spectrosc. 1991. 45. 1199.

25. Chervet. J. P: van Soest, R. E. J.; Ursem, M. J. Clwomatogr: 1991. 543.439.

26. Moring. S. E.: Reel. R. T.: van Soest. R. E. J. Anal. Chem. 1993. 65.3454 .

27. Kim. S.: Kim. W: Hahn. J. H. J. Chronatogr. A 1994. 680. 109

28. Hahn. J. H.: Kim, S.; Kim. W. Korea Patent 132100.

29. Handbook of Capilhay Electrophonsis. 2nd ed.; Landers. J. P.. Ed.; CRC Press: New York. U.S.A.. 1997: p 392.

30. Heiger. D. N. High Perforntance Capillary Electrophoresis atn Introduction: Hewlett-Pachard: Waldbront1. 1992: p 95.

31. Handbook of Capillary Electrophoresis: Landers. J. P. Ed: CRC Press: New York. U.S.A.. 1994, p 268. 